\title{
Culturally Responsive: Exploring the Attributes of Islamic Health Communication
}

\author{
Mohd Khairie Ahmad ${ }^{1,{ }^{*}}$,Mohd Baharudin Othman ${ }^{2}$,Nor Hayati Mohd Jalil ${ }^{3}$, and \\ Solahuddin Ismail ${ }^{4}$ \\ ${ }^{1,2,3}$ School of Multimedia Technology and Communication, College of Art and Science, Universiti \\ Utara Malaysia. \\ ${ }^{4}$ School of Government, Universiti Utara Malaysia
}

\begin{abstract}
The purpose of this paper is to explore the attributes (basis and values) of faith-based communication strategy on health communication. Eight series of focus group studies on Muslim community were conducted to gather the data. The finding makes abundantly clear that the tawhidic (the belief in Oneness of God) conception significantly determine the effectiveness of Islamic communication message. In addition, there were another six themes that contributes to Islamic health communication attributes which may influence the receiver's attitudes and behaviours. The insights of this paper may contribute to the further development of health promotion strategies for Muslims community.
\end{abstract}

\section{INTRODUCTION}

In acceptance of the reality that many Muslim nations are fronting substantial health-related issues, World Health Organisation (WHO) in collaborations with several Muslim organisations have recognised vision and approaches that culturally sensitive to the Muslim community. Based on the Ottawa Charter, the Amman Declaration in 1989 was marked as an international agenda in promoting health for Muslim community [1]. The purposes and attributes of Islamic communication (IC) are rooted in Islam's social fabric, and are believed to influence on health practices. Islamic communication approaches have put forth as important impacts on the targeted group health behaviour [2]. The purpose of this paper is to explore basis and values of health communication from a community that religiously closes. This article contributes to health communication literature by illustrating an applied case of intersecting local culture (Muslim community) for health issues in general.

\section{Literature review}

Awareness that culture should be taken into consideration in the ways in which health communication is theorised and practised is growing. There are two distinct yet interrelated approaches to health promotion efforts: the cultural sensitivity approach $[3,4]$ and the culture-centred approach $[5,6]$. The cultural sensitivity approach is conceptualised as

\footnotetext{
*Corresponding author: khairie@uum.edu.my
} 
developing culturally appropriate health communication practices that would adjust attitude, beliefs, and behaviours of the target audience. More precisely, it is a process of adapting messages to the cultural attributes of the dedicated group. The culture-centred approach pinpoints culture as the core element in theorising about the communication process. By way of explanation, communication theories develop from within the community values and characteristics instead of originating from outside. Explanation of scenario and enunciation of pragmatic solutions based on the landscape of the phenomena emerge from within the culture or subculture that being studied [3]. Yet, both the cultural sensitivity and cultural-centred approaches seek to answer to the call for consolidating culture in health communication practices.

Religiosity relates to the effect of social referents and thus can be understand as comparable to construct from the Theory of Planned Behaviour [7]. Relating health messages to religious matter, or using religious features on messages, may be applicable motivational strategies. This can be done through influence of social elements such as connecting health behaviours to particular sacred commandments or using the norms of the belief as a basis of encouraging or destructive sanctions [8]. As confirmed by Campbell, Demark-Wahnefried, Symons, Kalsbeek, \& et al. [9, 10], affirming individual feelings of religious superiority or disgrace can appeal attitudes towards wellbeing behaviours.

Grounded on discussion and dialogue on the Amman Declaration, it was established that there are at least sixty topics of health associated issues, rules, standard or guidance found in the two Muslim main sources (Quran and prophet teachings) which can be employed in producing health promotion messages. The Quran have at least 92 verses in that offer health messages which covered range of health issues [1]. There were also around 158 sunnah (prophet teachings) references found related to the health messages.

Generally, there are three approaches in promoting health from Islamic viewpoint: [11, 12]. Firstly, is the legal approach; it advocates particular rules of the religion that encourage health and prohibits activities that are destructive and risky to individual. Secondly is guiding method that claimed Islam to be a way of life. There is provision of particular protocols and guidelines which monitor individuals on their daily routines in Islam. The healing effect of the Quran is identified as the third approach. Recitation of certain Quran's verses is believed to provide a healing effect of human body system. Conversely, as emphasised by Al-Awwa [13], the Quran is not a medical book. It provides advices to safeguarding happiness and health to mankind through submitting the orders and steering away from the activities it's prohibits. These references offer potential coaching that can stimulus their actions and improve individual health conditions. Islam is equally a religion and a lifestyle that significantly affects Muslim's behaviour. Islam also provides direction not only in divine matters, but also in day-to-day life as well as well-being. The WHO has acknowledged the function of spiritual aspect in encouraging good wellbeing in accordance to Ottawa Charter [9].

\section{Study design}

This study employed the focus group technique, which is a procedure of group discussion and interaction among participants. Focus group discussions, usually supported with indepth interviews, are the most prominent tool likely to gain insight into the experiences, beliefs, attitudes and feelings that underlie people's behaviour [15, 16]. Forty eight Muslim participated in this study which formed into eight groups. Every group is set to be six participants. They will be established into primary school children (male), primary school children (female), secondary school children (male), secondary school children (female), adult age 18 to 25 (male), adult age 18 to 25 (female), adult age 26 to 40 (male) and adult age 26 to 40 (female). All focus group sessions were transcribed and analysed using 
thematic analysis technique. Data were transcribed, coded and analysed using qualitative analysis software, NVivo version 8 . The process contributes to identification of themes and trends that developed health communication attributes. Dovetailing with the study's aim, conceptual and relational content analysis techniques were performed on the data $[15,17]$. Mentioned analyses offer description and probe the relationship between the concepts identified [18]. Unit analysis for this study could be a word, sentence, sequence of sentences or a complete dialogue related to feelings, attitudes and reactions towards Islamic health messages. A category and coding scheme were developed to classify the content.

\section{Findings}

Analysis of focus groups found there were 108 references have emerged to explain the characteristics. Thematic analysis of the conversations discovered seven key themes: (i) Quran, (iii) sunnah, (iv) dakwah, (v) ammar makruh nahy munkar, (vi) tawhid, (vii) Muslim's opinion leader, and (vii) media. Analysis also found that education background does not have a significant impact on perceptions of Islamic communication attributes. From the thematic analysis, as illustrated in Figure 1, the key themes of Islamic health promotion were noted by all groups irrespective of their background. This indicates that in general, Muslims regardless of their religiosity had similar perceptions of Islamic communication characteristics.

\subsection{Tawhid (attributing oneness of God)}

This theme was among the Islamic communication characteristics that were mentioned by all groups. Tawhid which is the core philosophy of Islamic theology plays a very crucial role in persuading Muslims. Participants for the focus groups claimed that this attribute signified an Islamic form of communication. It is because in Islam anything and everything is about their religion and submission to their God. Communication with tawhidic doctrine not only symbolised Islam, but also indicated the first pillar of Islam which is belief in Allah. Psychologically, it creates some persuasion elements that are able to motivate Muslims to act upon the received message. Tawhidic content in the message consciously or unconsciously influences the receiver as it manifests God [19].

\subsection{Quran (Muslim holy book)}

The analysis showed that the Quran and Muslim opinion leaders appeared to be the most mentioned Islamic communication characteristics. Each of the characteristics represents about twenty per cent of total nodes related to the Islamic communication. All groups felt that the Quran is something that cannot be separated from a message that claims to be Islamic. Participants felt that communication in Islam should contain verses from the Quran or its interpretation or its teachings. Indeed, some participants felt that the narrative in the Quran can motivate Muslims to change their behaviour. What is most important is that the Quran is considered to be Allah's words, and guides Muslims in how to live their lives. Although some might think using the Quran is a conservative approach, it is a Muslim tradition that has not changed for the past 1400 years [20]. 


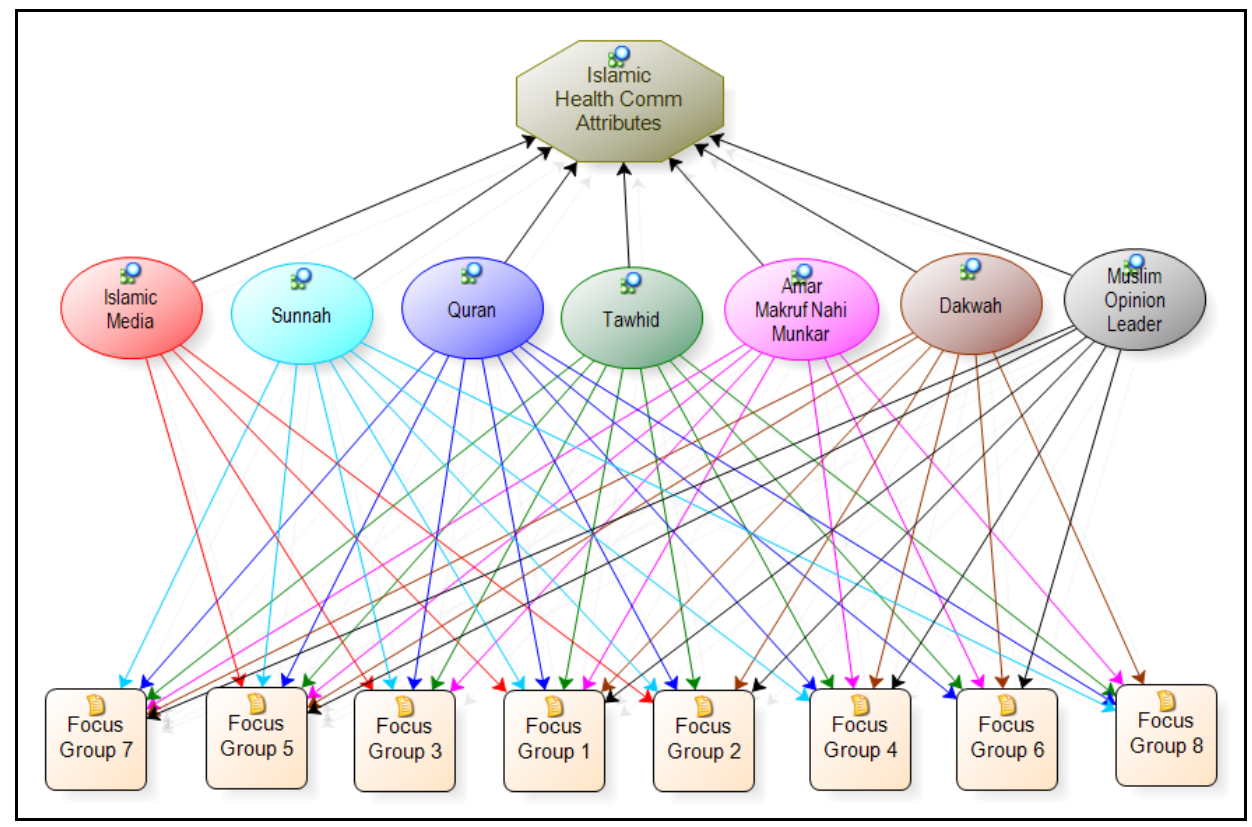

Fig. 1. Islamic Health Communication Attribute Themes

\subsection{Sunnah (Prophet Muhammad's sayings and deeds)}

As predicted according to previous findings, sunnah has been identified by this study as representing an important characteristic of Islamic communication. This third highest ranking attribute was discussed in all groups except group 5. In brief, sunnah was the second source of Islamic revelation and it refers to Prophet Muhammad's speeches or actions. Analysis of this attribute reveals that sunnah is a source of principles and teachings in Islam related to health issues. This is linked to participants' claims of using the Prophet Muhammad's quotations or actions about health in the campaign's messages. In fact some participants recommended that sunnah be used together with clinical or scientific evidence in order to have more impact. Participants of groups 3 and 4 even discussed hadith about the eating practices and food preferences of the Prophet Muhammad when explaining this characteristic.

\subsection{Amar Makruf Nahy Munkar (commanding good and prohibiting evil)}

This characteristic revealed in this focus group study supported previous study about what shapes Islamic communication [21]. Amar makruf nahy munkar (commanding to do good and prohibiting from doing wrong) refers to messages that guide Muslims. It also has been interpreted as the way of communicating ethical doctrine [22]. Based on the analysis, participants have suggested Islamic elements such as hukm (Islamic commandments), Islamic principles, treatment method, and preventive messages, to be used when communicating about health.

\subsection{Dakwah (Islamic preaching)}


According to respondents, dakwah is linked to the principle of Islam as a way of life. Thus, elements of communication in Islam transmit its religious mission through sacred information and teachings. Dakwah can be explained as Islamic teaching, enhanced faith, teaching to be a real Muslim, and the improvement process of a Muslim. The values of dakwah are not only to convert others to Islam but also an effort to strengthen Muslims' belief in Islam in all aspects of life.

\subsection{Muslim Opinion Leaders}

Another most described characteristic is Muslim opinion leader. Participants have classified ustaz/ustazah (religious teacher), imam (religious leader), and ulama (religious scholar) as people who influence the opinions of Muslims. Participants recognised these leaders as being credible and capable of influencing the community's opinion on issues related to Islam. Analysis of participant's conversation explained that these opinion leaders can influence Muslims through their popularity, being role models, their status in the community, their knowledge, and expertise. Furthermore, the Quran tells Muslims to follow these leaders as their authority is only exceeded by the prophet and his companions. The attributes of Muslim opinion leaders in health communication programs include their opinion, advice, decisions, remarks, and personal appearance or popularity as well.

\subsection{Media}

Media is another characteristic that emerged in the findings. This characteristic was perceived mainly by groups from the Islamic education background. Analysis of the coded conversation related to this character showed participants felt the Islamic health communication should be channelled through what they called 'Islamic media'. From the data gathered, it can be interpreted there are many media channels for health promotion. Among the media mentioned were Friday sermons, religious talk, masjid (mosque), and Islamic broadcasting channels. Their argument for the need to communicate through this media was based on credibility and effectiveness. While quite numbers of participants favoured traditional media, the new media has been identified as very potential to reach Muslim community.

\section{Conclusions}

Generally, this study has recognised the attributes of culturally based health communication (Islamic health communication) of the Muslim community. These attributes emerged across the focus group that representing young and adult Muslims community. This finding is supporting the call for innovation in social change such as in health promotion [23]. Therefore, it is recommended that further study be undertaken of this scenario by investigating if and how Islamic understanding, knowledge and skills affect the implementer's faith-based communication performance. This scope can be expanded to doctors, nurses, and other health professionals, as well as health activists. The study of Islam as culturally sensitive in health promotion is intriguing but as yet has received little research coverage. As this study explains, Islamic communication has potential and is found to positively impact Muslim practices such as health behaviour. This has particular relevance as many Muslim communities are now facing challenges in their health related issues. In this respect, there are still many research topics that can be approached through the Islamic communication framework developed here to mediate social change such as health issues in a Muslim community. The insights of this paper may contribute to the 
further development of health promotion strategies for Muslims in Islamic nations as well as in non-Islamic nations.

\section{References}

1. WHO, Health Promotion Through Islamic Lifestyles: The Amman Declaration (Alexandria: World Health Orgaisation, 1996)

2. M.K. Ahmad, \& J. Harrison, Cultural sensitivity in health promotion programs: Islamic persuasive communication. In Y. Pasadeos (Ed.), Advances in communication and mass media research, 167-180 (Athens: ATINER, 2010)

3. T.L. Thompson, R. Parrott, \& J.F. Nussbaum (eds.), The Routledge handbook of health communication (Oxon: Taylor \& Francis, 2011)

4. K.B. Wright, L.S. Sparks, \& H.D. O'Hair. Health communication in the $21^{\text {st }}$ century (West Sussex: John Wiley \& Sons, 2013)

5. C. Airhihenbuwa, Health and culture: Beyond the western paradigm (Thousand Oak: Sage Publications, 1995)

6. M.T. Dutta-Bergman, Communication Theory, 14(3), 237-263 (2004)

7. I. Ajzen. Persuasive communication theory in social psychology: A historical perspective. Influencing human behaviour, 1-27 (1992)

8. K. Glanz, B.K. Rimer, \& F.M. Lewis, (eds.), Health Behavior and Health Education: Theory, Research and Practice (San Francisco, CA: Jossey-Bass, 2002)

9. M.K. Campbell, W. Demark-Wahnefried, M. Symons, W.D. Kalsbeek, \& et al., Fruit and vegetable consumption and prevention of cancer: the Black Churches United for Better Health project. Am. J. Public Health. 89(9), 1390 (1999)

10. M.H. Al-Khayat, Health: An Islamic Perspective (Egypt: World Health Organization, 1997)

11. S. Sipon, M.F. Sakdan, C.S. Mustaffa, N.A. Marzuki, M.S. Khalid, M.T. Ariffin, N.N.N. Nazli, \& S. Abdullah, Spirituality among Flood Victims: A Comparison between Two States. Procedia-Social and Behavioral Sciences 185, 357-360 (2015)

12. A. El-Kadi, What Is Islamic Medicine. (1996)

13. M. Al-Awwa, Health in Islamic Literature. (2002)

14. E. De Leeuw, \& A.A. Hussein, Islamic health promotion and interculturalization. Health Promot. Int., 14(4), 347-353 (1999)

15. F. Rabiee, Focus-group interview and data analysis. Proceedings of the Nutrition Society, 63, 655-660 (2004)

16. D.W. Stewart. \& P.N. Shamdasani, Focus groups: Theory and practice (Newbury Park: Sage Publications, 1990)

17. Krippendorff, K, Content analysis: An introduction to its methodology (2nd. ed.) (Thousand Oaks: Sage, 2004)

18. M.E. Palmquist, K.M. Carley, \& T.A. Dale, Two applications of automated text analysis: Analyzing literary and non-literary texts. In C. Roberts (Ed.), Text Analysis for the Social Sciences: Methods for Drawing Statistical Inferences from Texts and Tanscripts (New Jersey: Lawrence Erlbaum Associates, 1997)

19. Y. Mohamed, The American Journal of Islamic Sciences, 12(1), 1-18 (1995)

20. J. Esposito, What everyone needs to know about Islam (Oxford: Oxford University Press, 2002)

21. M.K. Ahmad, J. Harrison, \& C.L. Davies, Sacred communication: Exploring the attributes of health promotion programs in the faith-based media' in M. Buyong, et. al. (eds.). Potrayal of Islam in the media (Nilai: University Sains Islam Malaysia, 2010) 
22. H. Mowlana, Theoretical perspectives on Islam and communication. China Media Research, 3(4), 23-33 (2007)

23. C. Mason, J. Barraket, S. Friel, K. O'Rourke \& C. Stenta, Social innovation for the promotion of health equity. Health Promot. Int., 30(2), 116-125 (2015) 